\title{
Reviewing the options for local estrogen treatment of vaginal atrophy
}

\author{
This article was published in the following Dove Press journal: \\ International Journal of Women's Health \\ 13 March 2014 \\ Number of times this article has been viewed
}

\author{
Sarah H Lindahl \\ Sutter East Bay Medical Foundation, \\ SEBMF - Diablo Division, Castro \\ Valley, CA, USA
}

Background: Vaginal atrophy is a chronic condition with symptoms that include vaginal dryness, pain during sex, itching, irritation, burning, and discharge, as well as various urinary problems. Up to $45 \%$ of postmenopausal women may be affected, but it often remains underreported and undertreated. This article aims to review the current recommendations for treatment of vaginal atrophy, and current data on the effectiveness and safety of local vaginal estrogen therapies.

Methods: Literature regarding vaginal atrophy (2007-2012) was retrieved from PubMed and summarized, with emphasis on data related to the treatment of vaginal atrophy with local vaginal estrogen therapy.

Results: Published data support the effectiveness and endometrial safety of low-dose local estrogen therapies. These results further support the general recommendation by the North American Menopause Society that a progestogen is not needed for endometrial protection in patients using low-dose local vaginal estrogen. Benefits of long-term therapy for vaginal atrophy include sustained relief of symptoms as well as physiological improvements (eg, decreased vaginal $\mathrm{pH}$ and increased blood flow, epithelial thickness, secretions).

Conclusion: Currently available local vaginal estrogen therapies are well tolerated and effective in relieving symptoms of vaginal atrophy. Recent data support the endometrial safety of low-dose regimens for up to 1 year.

Keywords: menopause, estrogen, local estrogen therapy, vaginal atrophy

\section{Introduction}

Before menopause, estrogen stimulates the exfoliation of vaginal cells. As these cells exfoliate and die, they release large amounts of glycogen. This glycogen is hydrolyzed to glucose and lactobacillus converts the glucose to lactic acid, which helps maintain vaginal $\mathrm{pH}$ between 3.5 and 4.5. ${ }^{1}$ After menopause, with declining levels of estrogen, this pathway is less active, which may allow postmenopausal $\mathrm{pH}$ to increase to the range of 5.0-7.5. ${ }^{1}$ At these higher $\mathrm{pH}$ levels, lactobacillus survival is hindered, and vaginal colonization by other bacterial species predisposes women to symptomatic vaginal infection or urinary tract infection. ${ }^{2}$

Vaginal atrophy is a chronic condition resulting from a decline in estrogen in the urogenital tissues that affects up to $45 \%$ of postmenopausal women. ${ }^{3,4}$ Vaginal atrophy presents as thin, pale, and dry vaginal walls; reduced elasticity of vaginal tissue; loss of rugae; and a shortened and narrowed vagina. Symptoms include vaginal dryness, pain during sex, bleeding during intercourse/touching, itching, irritation, burning, and discharge, as well as various urinary problems, including increased frequency, urgency, incontinence, dysuria, and infection. ${ }^{2,5}$ These signs and symptoms can have
Correspondence: Sarah $\mathrm{H}$ Lindah Sutter East Bay Medical Foundation, 20 I0I Lake Chabot Blvd, Castro Valley, CA 94546, USA

Tel + I 5I0 8863400

$\mathrm{Fax}+I 5105816517$

Email shlindobgyn@yahoo.com 
an enormous impact on a patient's well-being, especially in the context of sexual function. ${ }^{6}$ Lack of lubrication with sexual intercourse causes dyspareunia, which can lead to avoidance of healthy sexual activity and to further atrophy. A woman with vaginal atrophy may also experience bleeding with minimal trauma, such as during a medical examination or exercise.

The lower urinary tract is also directly affected by decreased estrogen, as estrogen receptors are found throughout the epithelial tissues of the urethra, trigone, and bladder, and in some of the surrounding muscles and ligaments. ${ }^{7,8}$ Thinning of the urinary epithelium and weakening of the surrounding tissue may promote reduced urethral closure pressure, reduced sensory threshold in the bladder, and, in some cases, recurrent urinary tract infection. ${ }^{8}$

Typically, a diagnosis of vaginal atrophy can be made from clinical examination, with many women presenting with dry, glazed-looking vaginal epithelium; a thinning cervix; a loss of labial fat pad; or a vagina that has lost elasticity, has shortened, has narrowed, has become less distensible, and can be easily traumatized and irritated. ${ }^{5,9}$ Diagnosis may be further supported by $\mathrm{pH}$ or the vaginal maturation index (VMI), which indicates the relative proportion of parabasal cells, intermediate cells, and mature superficial cells of the vaginal squamous epithelium, and is calculated based the following formula: $\mathrm{VMI}=0.5\left(\mathrm{X}_{2}\right)+$ $1\left(X_{3}\right)$, where $X_{2}=\%$ intermediate cells and $X_{3}=\%$ superficial cells. ${ }^{10}$ The VMI is $0 \%-49 \%$ in patients with an absent or low estrogenic effect, $50 \%-64 \%$ in patients with a moderate estrogenic effect, and $65 \%-100 \%$ in patients with a high estrogenic effect. ${ }^{10}$

While the vasomotor symptoms of menopause generally improve over time, vaginal symptoms usually worsen and do not improve without treatment. ${ }^{5}$ Women may attribute these changes to be a part of "normal aging" and may not be aware of safe and simple treatments. Only about $25 \%$ of women who experience symptoms of vaginal atrophy seek medical help. ${ }^{9}$ As vaginal infections should be part of the differential diagnosis, ${ }^{1}$ vaginal atrophy may be misdiagnosed by patients and providers as a vaginal infection caused by yeast or bacteria. Obtaining a thorough history and performing an examination should help to avoid misdiagnosis and delaying treatment in postmenopausal patients experiencing some or all of these symptoms.

The goal of this article is to provide an overview of the current recommendations for treatment of vaginal atrophy, followed by a succinct review of the effectiveness and safety of local vaginal estrogen therapies.

\section{Methods}

PubMed was initially searched using the terms "vaginal" and "atrophy." To find recent publications focused on the influence of estrogen in the lower urinary tract that may not have been located in the main search, the terms "urogenital," "atrophy," and "estrogen" were used. Relevant literature (restricted to works in English and published after January 1, 2007) was reviewed and summarized, with emphasis on data related to treatment with local vaginal estrogen therapy. In addition, references cited within the relevant literature sources identified in the literature search were reviewed for content related to estrogen therapy and considered for use as original data sources. Recommendations from the American Congress of Obstetricians and Gynecologists (ACOG) and the North American Menopause Society (NAMS) were also consulted.

\section{Recommendations for the treatment of vaginal atrophy}

According to NAMS, first-line treatment for vaginal atrophy should include nonhormonal vaginal lubricants and moisturizers, as well as continued sexual activity. ${ }^{5}$ Regular sexual activity helps maintain active blood flow to the vagina and helps produce vaginal lubrication. Moisturizers, such as Replens (Lil' Drug Store Products, Inc., Cedar Rapids, IA, USA), are intended for regular use, while lubricants, such as K-Y (McNeil-PPC, Inc., Fort Washington, PA, USA) or Astroglide (BioFilm, Inc., Vista, CA, USA), are intended for use during sexual activity. Replens has been shown to increase vaginal moisture, fluid volume, and elasticity, while decreasing $\mathrm{pH} .^{11}$

In addition, Osphena (Shionogi Inc., Florham Park, NJ, USA), an estrogen agonist/antagonist, is an oral treatment for moderate to severe dyspareunia that was approved by the US Food and Drug Administration in February $2013 .^{12}$

The Vaginal Health: Insights, Views and Attitudes (VIVA) survey was designed to assess the knowledge of vaginal atrophy in postmenopausal women with the goal of increasing awareness of vaginal atrophy, aiding in increasing physician-patient dialogue, and therefore allowing women to make better-informed treatment decisions. ${ }^{13}$ Among the 1,578 respondents who reported experiencing vaginal discomfort, 49\% reported trying lubricating gels and creams; $22 \%$ reported not using any treatment. ${ }^{13}$

Although over-the-counter treatments may work for women with mild symptoms, they are often inadequate for women with moderate to severe symptoms. If nonhormonal 
options are not sufficient, ACOG has also noted that estrogen therapy, whether topical (local) or systemic, is an effective treatment for vaginal dryness or atrophic changes that impede sexual function. ${ }^{14}$

Although many systemic estrogen hormone products are approved for the prevention of osteoporosis and the treatment of moderate to severe vasomotor symptoms associated with menopause, there is a risk for deep vein thrombosis, pulmonary embolism, coronary heart disease, and endometrial and breast cancer. ${ }^{15-18}$ Long-term systemic hormone therapy is no longer recommended if considered solely for the treatment of vaginal atrophy, and therefore local vaginal estrogen therapy is advised. ${ }^{5}$ Low-dose, local vaginal estrogen therapy reduces the risk associated with long-term systemic estrogen exposure, and is effective and well tolerated in most women. ${ }^{5}$

\section{Efficacy and safety of local vaginal estrogen treatment}

Four local vaginal estrogen treatments are available in the United States for the treatment of vaginal atrophy (two vaginal creams, one vaginal ring, and one vaginal tablet). They are well tolerated and considered equally effective by NAMS. ${ }^{5}$ In the VIVA survey, $13 \%$ of respondents who reported experiencing vaginal discomfort reported they had used vaginal hormone creams, $12 \%$ reported they had used vaginal hormone tablets, and $1 \%$ reported having used a vaginal hormone ring. ${ }^{13}$ Because vaginal estrogens fall into the general category of estrogen therapies, package inserts on local vaginal estrogen treatments carry the same warnings as systemic estrogens. The following sections aim to provide a concise review of the most recent and relevant data concerning the efficacy and safety of local vaginal estrogen treatments.

\section{Vaginal creams}

Two vaginal creams are available: Premarin ${ }^{19}$ (Wyeth Pharmaceuticals Inc., part of Pfizer, Inc., New York, NY, USA) and Estrace ${ }^{20}$ (Warner Chilcott [US], LLC, Rockaway, NJ, USA). Premarin vaginal cream contains $0.625 \mathrm{mg}$ conjugated equine estrogens (CEE) per gram of cream. Its composition is unique in that it does not solely contain estradiol as the active ingredient. CEE cream contains a mixture of estrogenic compounds, predominantly estrone, equilin, $17 \alpha$-dihydroequilin, $17 \alpha$-estradiol, and $17 \beta$-dihydroequilin. ${ }^{19}$ Recommended dosing is $0.5-2.0 \mathrm{~g}$ once daily for 21 days, followed by 7 days without treatment (repeated in a 28 -day cycle) or 0.5 g twice weekly. In a randomized, placebo-controlled study, postmenopausal women with moderate to severe vaginal atrophy who received low-dose CEE cream ( $0.3 \mathrm{mg} \mathrm{CEE}$, equivalent to $0.5 \mathrm{~g}$ Premarin vaginal cream) according to either the cyclic or the twice-weekly regimen exhibited improved VMI, improved vaginal $\mathrm{pH}$, and improved most bothersome symptom scores, including those for dyspareunia, at week 12 of treatment. ${ }^{21}$ After the initial 12 weeks, open-label treatment was continued for 40 weeks, consistent with the patient's prior regimen. Endometrial hyperplasia or carcinoma did not develop in any patients, based on 155 biopsy samples, and the CEE and placebo groups reported adverse events (AEs) of similar type and frequency. None of the serious AEs were considered related to the study drug.

Estrace $^{20}$ contains $0.1 \mathrm{mg}$ estradiol per gram of cream and recommended dosing is 2-4 g daily for 1-2 weeks, a gradual reduction to half the initial dose over 1-2 weeks, and then $1 \mathrm{~g}$ 1-3 times weekly for maintenance. For the initial period of treatment, it is important to adhere to the medication schedule while waiting for a response. No randomized controlled trials have been performed, and no results of observational studies have been published in the past 10 years.

\section{Vaginal ring}

The Estring ${ }^{22}$ vaginal ring (Pharmacia and Upjohn Company, Division of Pfizer, Inc., New York, NY, USA) contains a 2 mg estradiol reservoir. When inserted into the upper third of the vagina, the ring releases approximately $7.5 \mu \mathrm{g}$ per day for 90 days. In an open-label study, women using Estring for 12 months experienced an improvement in qualitative cytological evaluations (generally atrophic at baseline to proliferative [moderate estrogen effect] or highly proliferative [high estrogen effect] at week 48). ${ }^{23}$ Patient-reported symptoms and clinical signs on inspection improved greatly. The primary endpoint - endometrial safety — was assessed at baseline and at week 48 by ultrasound measurement of endometrial thickness and a progestogen challenge test. ${ }^{23}$ In women using Estring, the mean endometrial thickness remained constant, and no women experienced withdrawal bleeding or spotting during the progestogen challenge test. Only two of 126 women had significant endometrial thickening (13.0 and 19.0 $\mathrm{mm}) .{ }^{23}$ One of these women had a uterine myoma, while the other experienced a rapid reduction in endometrial thickness to $4 \mathrm{~mm}$ without bleeding; neither had evidence of proliferation on endometrial biopsy. The low-dose Estring should not be confused with Femring ${ }^{24}$ (Warner Chilcott [US]), a vaginal ring that delivers systemic levels of estrogen replacement. Less than $2 \%$ of women experience ulcers with vaginal rings ( 2 of 136 women in a 1 -year study). ${ }^{25}$ 


\section{Vaginal tablet}

The Vagifem ${ }^{26}$ vaginal tablet (Novo Nordisk A/S, Bagsvaerd, Denmark) contains $10 \mu \mathrm{g}$ estradiol. This ultra-low-dose vaginal tablet, introduced in 2010 , replaced a $25 \mu \mathrm{g}$ vaginal tablet that was previously available. As both regulatory authorities and therapeutic experts from menopause societies agree that the minimum effective dose of estrogen should be used for the treatment of vaginal atrophy, 5,27,28 the ultra-low-dose $(10 \mu \mathrm{g})$ vaginal tablets were developed to provide symptom relief while reducing systemic exposure to estrogen. The recommended dosing schedule of Vagifem $10 \mu \mathrm{g}$ is one tablet daily for 2 weeks, followed by one tablet twice weekly for maintenance, with an annual estrogen exposure of $1.14 \mathrm{mg} .{ }^{26}$ The efficacy and safety of this ultra-low-dose regimen for the treatment of vaginal atrophy in postmenopausal women has been established in recent studies. ${ }^{29-31}$ At 12 weeks of treatment, significant improvement in VMI, maturation value, grading of vaginal health, vaginal $\mathrm{pH}$, and most bothersome symptom score was seen. ${ }^{29}$ Improvement over baseline was maintained through 52 weeks. One participant (from 164 treated participants completing the study) lacked an evaluable biopsy at baseline and was found to have endometrial adenocarcinoma stage II, grade 2 after approximately 10 months of treatment; de novo development was considered unlikely because of the clinical time frame. ${ }^{29}$ To further assess safety, endometrial biopsy was performed at the beginning and end of a 52-week study. ${ }^{30}$ No endometrial hyperplasia or endometrial cancer was found. Over the course of the study, endometrial thickness measured by transvaginal ultrasound decreased from $2.04 \mathrm{~mm}(\mathrm{n}=334)$ to $1.94 \mathrm{~mm}(\mathrm{n}=293)$, which may reflect the expected decrease in thickness with age, with no interfering endometrial stimulation. ${ }^{30}$ None of the serious AEs were considered related to the study drug. A larger pooled analysis (based on 386 evaluable biopsy samples) determined that ultra-low-dose estradiol vaginal tablets did not increase the risk for endometrial hyperplasia or carcinoma in postmenopausal women for 1 year under study conditions. ${ }^{31}$

\section{Lack of need for progesterone}

In its 2013 position statement, NAMS stated that the primary indication for progesterone is to reduce the risk of endometrial cancer and should be used in patients who are on systemic estrogen therapy and have an intact uterus. ${ }^{5}$ However, progesterone is "generally not indicated when lowdose vaginal estrogen is administered." Because low doses of vaginally administered estrogen, such as those delivered by a low-dose CEE regimen, ${ }^{21}$ the vaginal ring, ${ }^{23}$ and the vaginal tablet, ${ }^{31}$ have not been associated with increased risk for endometrial hyperplasia, progestogen is not generally indicated when local estrogen products are administered. ${ }^{5}$ However, no recommendations have been made regarding the need for progesterone with creams that deliver higher doses

Table I Recent clinical trials assessing the safety of local vaginal estrogen therapies

\begin{tabular}{|c|c|c|c|c|c|}
\hline Product & $\mathbf{N}$ & Duration and design & Treatment groups & Safety assessment & Reference \\
\hline $\begin{array}{l}\text { Premarin } \\
\text { vaginal cream }\end{array}$ & 423 & $\begin{array}{l}\text { I2-week double-blind } \\
\text { phase, followed by } \\
40 \text {-week open-label } \\
\text { phase consistent with } \\
\text { previous regimen }\end{array}$ & $\begin{array}{l}\text { Premarin cream ( } 0.3 \mathrm{mg} \text { CE) or placebo } \\
\text { cream once daily ( } 2 \text { I days on/ } 7 \text { days } \\
\text { off) or twice weekly (first } 12 \text { weeks), } \\
\text { then all women taking Premarin } \\
\text { cream according to prior regimen }\end{array}$ & $\begin{array}{l}\text { No hyperplasia or carcinoma, as } \\
\text { assessed by transvaginal ultrasound } \\
\text { and endometrial biopsy } \\
\text { Adverse event frequency similar to that } \\
\text { of placebo during double-blind phase }\end{array}$ & 21 \\
\hline
\end{tabular}

Estrace vaginal No recent trials

cream

Estring vaginal $126 \quad$ I2-month open-label
ring

ring

Vagifem vaginal $309 \quad 52$-week double-blind tablet

336 52-week open-label

\begin{abstract}
Estring vaginal ring $(7.5 \mu \mathrm{g}$ estradiol released daily) compared with Vagifem vaginal tablet $(25 \mu \mathrm{g}$ estradiol, which has since been discontinued and replaced by a $10-\mu \mathrm{g}$ estradiol version) daily for 2 weeks, then twice weekly

Vagifem vaginal tablet ( $10 \mu \mathrm{g}$ estradiol) or placebo tablet assigned in 2:I ratio daily for 2 weeks, then twice weekly Vagifem vaginal tablet ( $10 \mu \mathrm{g}$ estradiol) daily for 2 weeks, then twice weekly
\end{abstract}

No increase in average endometrial thickness

No bleeding/spotting in Estring group with PCT

No major safety findings regarding physical, gynecologic, or laboratory assessments

No cases of endometrial hyperplasia or endometrial cancer Decrease in mean endometrial thickness

Abbreviations: $\mathrm{CE}$, conjugated estrogens; $\mathrm{PCT}$, progestogen challenge test. 
of estrogen. Key safety information from recent clinical trials is summarized in Table 1.

\section{Benefits of long-term therapy for vaginal atrophy}

All of the aforementioned treatments, when used as directed, are well tolerated and effective for relieving symptoms of vaginal atrophy. ${ }^{5}$ They provide vaginal estrogen, while minimizing systemic exposure, ${ }^{32-34}$ and result in increased blood flow, increased epithelial thickness, and increased secretions, as well as reduced $\mathrm{pH}^{5}$ These physiological improvements represent a reversal of atrophy and lead to a positive clinical outcome for most women.

The urogenital symptoms of estrogen deficiency that present in the postmenopausal years may require long-term therapy, since women have reported the return of symptoms during washout periods between different treatments, even after just a few weeks. ${ }^{32}$ Given the comparable efficiency of the low-dose, locally administered estrogen products, NAMS recommends that severity of symptoms, effectiveness and safety of therapy for the individual patient, and patient preference guide the choice of treatment. ${ }^{5}$ It is important that patients accept and adhere to their treatment in order to fully realize the benefits. Clinicians can be instrumental in educating patients about vaginal atrophy as a chronic condition; the advantages of low-dose, local vaginal estrogen therapy; and the importance of long-term management.

\section{Conclusion}

Vaginal atrophy is a common, underreported, and undertreated chronic condition that results from a decrease in estrogen levels during menopause. ${ }^{1}$ When over-the-counter treatments fail to relieve symptoms, NAMS recommends low-dose, local vaginal estrogen therapy. A variety of formulations (ie, creams, ring, and tablet) are available, and based on the collective results of many studies conducted over the past two decades, NAMS considers all of these effective and well tolerated. ${ }^{5}$

Because vaginal atrophy is a chronic condition, treatment should be continued for as long as symptoms persist and may need to be continued indefinitely. Long-term studies (up to 1 year) have shown that low-dose, local vaginal estrogen therapy has an excellent safety profile marked by no increased risk for endometrial hyperplasia, which is a common concern with estrogen-alone therapies. Such data should provide reassurance to women with vaginal atrophy who may otherwise hesitate to accept a hormonal form of treatment.
Finally, many women remain untreated because they avoid reporting symptoms of vaginal atrophy to their health care provider. Clinicians may take an active role in encouraging such discussions by asking their postmenopausal patients whether they have experienced any vaginal dryness or discomfort, with or without sexual activity. By initiating the conversation and then following up on any complaints with an examination or a referral, it may become easier to diagnose and appropriately treat postmenopausal women with vaginal atrophy.

\section{Acknowledgments}

Medical writing assistance was provided by Pamela Barendt, PhD, of ETHOS Health Communications, Newtown, Pennsylvania, with financial assistance from Novo Nordisk, Inc., in compliance with international guidelines for Good Publication Practice. The author received no remuneration of any kind for the development of this manuscript.

\section{Disclosure}

The author has no conflict of interest to report.

\section{References}

1. Mac Bride MB, Rhodes DJ, Shuster LT. Vulvovaginal atrophy. Mayo Clin Proc. 2010;85(1):87-94.

2. Stika CS. Atrophic vaginitis. Dermatol Ther. 2010;23(5):514-522.

3. Santoro N, Komi J. Prevalence and impact of vaginal symptoms among postmenopausal women. $J$ Sex Med. 2009;6(8):2133-2142.

4. Nappi RE, Kokot-Kierepa M. Women's voices in the menopause: results from an international survey on vaginal atrophy. Maturitas. 2010;67(3): 233-238.

5. Management of symptomatic vulvovaginal atrophy: 2013 position statement of The North American Menopause Society. Menopause. 2013;20(9):888-902.

6. Krychman ML. Vaginal estrogens for the treatment of dyspareunia. J Sex Med. 2011;8(3):666-674.

7. Robinson D, Cardozo L. Estrogens and the lower urinary tract. Neurourol Urodyn. 2011;30(5):754-757.

8. Hillard T. The postmenopausal bladder. Menopause Int. 2010;16(2): 74-80.

9. Sturdee DW, Panay N; International Menopause Society Writing Group. Recommendations for the management of postmenopausal vaginal atrophy. Climacteric. 2010;13(6):509-522.

10. Jaisamrarn U, Triratanachat S, Chaikittisilpa S, Grob P, Prasauskas V, Taechakraichana N. Ultra-low-dose estriol and lactobacilli in the local treatment of postmenopausal vaginal atrophy. Climacteric. 2013;16(3): 347-355.

11. Nachtigall LE. Comparative study: Replens versus local estrogen in menopausal women. Fertil Steril. 1994;61(1):178-180.

12. Osphena (ospemifene) [prescribing information]. Florham Park, NJ: Shionogi Inc.

13. Nappi RE, Kokot-Kierepa M. Vaginal Health: Insights, Views and Attitudes (VIVA) - results from an international survey. Climacteric. 2012;15(1):36-44.

14. American College of Obstetricians and Gynecologists, Women's Health Care Physicians. Hormone Therapy. Sexual Dysfunction. Obstet Gynecol. 2004;104(4):S85-S91. 
15. Scarabin PY, Oger E, Plu-Bureau G; EStrogen and THromboEmbolism Risk Study Group. Differential association of oral and transdermal oestrogen-replacement therapy with venous thromboembolism risk. Lancet. 2003;362(9382):428-432.

16. Lokkegaard E, Andreasen AH, Jacobsen RK, Nielsen LH, Agger C, Lidegaard O. Hormone therapy and risk of myocardial infarction: a national register study. Eur Heart J. 2008;29(21):2660-2668.

17. Canonico M, Plu-Bureau G, Lowe GD, Scarabin PY. Hormone replacement therapy and risk of venous thromboembolism in postmenopausal women: systematic review and meta-analysis. BMJ. 2008;336(7655):1227-1231.

18. Margolis KL, Bonds DE, Rodabough RJ, et al. Effect of oestrogen plus progestin on the incidence of diabetes in postmenopausal women: results from the Women's Health Initiative Hormone Trial. Diabetologia. 2004;47(7):1175-1187.

19. Premarin (conjugated estrogens) vaginal cream [prescribing information]. Philadelphia, PA: Wyeth Pharmaceuticals Inc, part of Pfizer.

20. Estrace (estradiol vaginal cream, USP, $0.01 \%$ ) [prescribing information]. Rockaway, NJ: Warner Chilcott (US), LLC.

21. Bachmann G, Bouchard C, Hoppe D, et al. Efficacy and safety of lowdose regimens of conjugated estrogens cream administered vaginally. Menopause. 2009;16(4):719-727.

22. Estring (estradiol vaginal ring) [prescribing information]. New York, NY: Pharmacia and Upjohn Company, Division of Pfizer Inc.

23. Weisberg E, Ayton R, Darling G, et al. Endometrial and vaginal effects of low-dose estradiol delivered by vaginal ring or vaginal tablet. Climacteric. 2005;8(1):83-92.

24. Femring (estradiol acetate vaginal ring) [prescribing information]. Rockaway, NJ: Warner Chilcott (US), LLC.

25. Henriksson L, Stjernquist M, Boquist L, Cedergren I, Selinus I. A oneyear multicenter study of efficacy and safety of a continuous, low-dose, estradiol-releasing vaginal ring (Estring) in postmenopausal women with symptoms and signs of urogenital aging. Am J Obstet Gynecol. 1996;174(1):85-92.
26. Vagifem (estradiol vaginal tablets) [prescribing information]. Princeton, NJ: Novo Nordisk Inc.

27. Birkhauser MH, Panay N, Archer DF, et al. Updated practical recommendations for hormone replacement therapy in the peri- and postmenopause. Climacteric. 2008;11(2):108-123.

28. US Department of Health and Human Services, Food and Drug Administration, Center for Drug Evaluation and Research (CDER). Guidance for industry: labeling guidance for noncontraceptive estrogen drug products for the treatment of vasomotor symptoms and vulvar and vaginal atrophy symptoms - prescribing information for health care providers and patient labeling. Available from: http://www.fda.gov/ downloads/Drugs/DrugSafety/InformationbyDrugClass/UCM135336. pdf. Accessed November 30, 2011

29. Simon J, Nachtigall L, Gut R, Lang E, Archer DF, Utian W. Effective treatment of vaginal atrophy with an ultra-low-dose estradiol vaginal tablet. Obstet Gynecol. 2008;112(5):1053-1060.

30. Ulrich LS, Naessen T, Elia D, Goldstein JA, Eugster-Hausmann M. Endometrial safety of ultra-low-dose Vagifem 10 microg in postmenopausal women with vaginal atrophy. Climacteric. 2010;13(3): 228-237.

31. Simon J, Nachtigall L, Ulrich LG, Eugster-Hausmann M, Gut R. Endometrial safety of ultra-low-dose estradiol vaginal tablets. Obstet Gynecol. 2010;116(4):876-883.

32. Bachmann $\mathrm{G}$. The estradiol vaginal ring - a study of existing clinical data. Maturitas. 1995;22(Suppl):S21-S29.

33. Eugster-Hausmann M, Waitzinger J, Lehnick D. Minimized estradiol absorption with ultra-low-dose 10 microg 17 beta-estradiol vaginal tablets. Climacteric. 2010;13(3):219-227.

34. Dorr MB, Nelson AL, Mayer PR, et al. Plasma estrogen concentrations after oral and vaginal estrogen administration in women with atrophic vaginitis. Fertil Steril. 2010;94(6):2365-2368.
International Journal of Women's Health

\section{Publish your work in this journal}

The International Journal of Women's Health is an international, peerreviewed open-access journal publishing original research, reports, editorials, reviews and commentaries on all aspects of women's healthcare including gynecology, obstetrics, and breast cancer. The manuscript management system is completely online and includes
Dovepress

a very quick and fair peer-review system, which is all easy to use. Visit http://www.dovepress.com/testimonials.php to read real quotes from published authors. 